\title{
Detection of Genetic Variation in Wild Populations of Three Allium Species Using Amplified Fragment Length Polymorphisms
}

\author{
Nathan C. Phillips ${ }^{1}$ \\ Middle Tennessee State University, School of Agribusiness and Agriscience, \\ Campus Box 5, Murfreesboro, TN 37132
}

\author{
Steven R. Larson \\ USDA-ARS, Forage and Range Research Laboratory, Utah State University, \\ Logan, UT 84322-6300
}

\author{
Daniel T. Drost \\ Utah State University, Plants Soils and Climate, Logan, UT 84322-4820
}

Additional index words. genetic diversity, germplasm, divergence, Allium acuminatum, Allium brandegei, Allium passeyi

Abstract. Three wild onion species native to the intermountain west in the United States-Allium acuminatum, A. brandegei, and $A$. passeyi-show horticultural potential, but little is known about patterns of genetic diversity among localized populations and geographical regions. We examined amplified fragment length polymorphisms (AFLP) within and among five Allium acuminatum, four $A$. brandegei, and three $A$. passeyi collection sites in Utah. These three congeners with contrasting abundance and distribution patterns provide an opportunity to investigate the role of geographic distance, altitude, and rarity in patterns of genetic divergence. The collection sites were selected along an altitudinal gradient to reflect ecogeographic variation. Individual plants from each of the 12 sites were genotyped using six AFLP primer combinations detecting DNA variation within and among all three species. Genetic differences between species were high enough to render comparisons among species impractical, so each species was analyzed separately for differences between populations and variability within populations. Similarity coefficients were significantly greater within collection sites versus among collection sites indicating divergence between populations. Within-population genetic diversity was not correlated with elevation for any of the three species. Analysis of molecular variance revealed that $66 \%$ (A. acuminatum), $83 \%(A$. passeyi), and $64 \%(A$. brandegei) of observed variation is found within populations. Genetic divergence among populations $\left(\Phi_{\mathrm{ST}}\right)$ was higher in the widely distributed species, suggesting that interpopulation gene flow may be negatively correlated with range size. Allium acuminatum and $A$. brandege $i$ individuals cluster into groups corresponding strictly to collection sites based on neighbor-joining analysis of the total number of DNA polymorphisms between individual plants. Allium passeyi populations, however, had less overall genetic variation between populations. Genetic isolation by distance appeared responsible for much of the variability among populations, although there was one notable exception showing significant differences between two geographically close populations in $\mathrm{A}$. acuminatum.

Efficient propagation of native intermountain plant species for rangeland restoration and other commercial uses requires some basic knowledge about natural genetic diversity in the landscape (Adair et al., 2006; Monsen and Shaw, 2001). The patterns of

\footnotetext{
Received for publication 8 Aug. 2007. Accepted for publication 13 Nov. 2007.

This research was supported by grants from the Utah Botanical Center, the Utah Native Plant Society, and by the Utah Agricultural Experiment Station, Utah State University, Logan, UT (journal paper no. 7909).

${ }^{1}$ To whom reprint requests should be addressed; e-mail nphillip@mtsu.edu
}

genetic diversity among localized populations and geographical regions needs to be better understood to help identify collections crucial for conservation and suitable for breeding efforts (Adair et al., 2006; Rio and Bamberg, 2002). Ideally, a crop gene bank collection would contain a representative core of a species germplasm, providing storage and access to the widest range of genetic traits. In conjunction with evaluations of life history, growth characteristics, demographics, and habitat of three intermountain Allium species native to Utah, we used the amplified fragment length polymorphism (AFLP) technique in investigating patterns of genetic diversity within and among the study populations. The description of our study offers information useful in strategies for identifying sources of intermountain Allium germplasm rich in genetic diversity.

The genus Allium has a worldwide distribution consisting of $\approx 700$ species, including $\approx 80$ species in North America (Brewster and Rabinowitch, 1990; Hanelt, 2001; Kamenetsky and Rabinowitch, 2006; McNeal and Ownbey, 1973; McNeal and Jacobsen, 2001). The genus includes economically important crop species such as onions, garlic, chives, leeks, and other minor crops. Allium species have also been traditionally used in the ornamental industry with occasional new species derived from natural populations being introduced into the trade (Kamenetsky and Rabinowitch, 2006). Virtually all cultivated Alliums are derived from old world species, and little is known about many North American species. Considering the economic and cultural importance of Alliums throughout history, and the wealth of biodiversity in the genus, it would be prudent to use genetically sound strategies for the collection of currently unexploited Allium germplasm.

Rising interest in the preservation of intermountain Allium germplasm has encouraged research to further our understanding of the genetic diversity found within and among species (Adair et al., 2006; Hellier, 2000). Growers depending on wild seed collection would benefit from understanding genetic variation in wild populations across the natural landscape. Knowing the extent of genetic diversity within and among populations provides information that might be useful in the selection of a seed collection site. Intermountain Allium species can vary considerably in their distribution, occurrence, and habitat. Although among-population genetic variation is often known to be a result of isolation by distance, the significance of correlations between geographic distribution and genetic diversity has been a topic of debate among biologists (Gitzendanner and Soltis, 2000; Hamrick and Godt, 1989; Karron, 1987). Recent studies have cast doubt on the theory that narrowly restricted or rare species necessarily exhibit lower levels of among-population genetic variation in comparison with widespread species (Bjerregaard, 2004). In comparing genetic variation in rare and widespread congeners compiled from the existing literature, there was no universal trend in levels of among-population genetic diversity in response to range size (Gitzendanner and Soltis, 2000). The authors did note high congeneric correlations for genetic measures, suggesting that it is useful to assess genetic variation in relation to range size within species of the same genus. Doing so allows one to investigate genera-specific relationships between range size and genetic variation within and among populations. Like range size, habitat variation may also play a role in the partitioning of genetic variation. Genetic differentiation in some species has also been shown to be closely related to altitude (Wen and Hsiao, 2001), whereas in other species, no such correlation was found (Bingham and Ranker, 2000). Ecotypic 
genetic variation may be detected within a species by sampling along an altitudinal gradient (Clausen et al., 1940). Understanding how genetic diversity is partitioned within and among intermountain Allium populations can give insight into the mechanisms that have influenced their current habitats as well as aid in the development of propagation protocol, seed transfer guidelines, and conservation management plans.

Previous studies of genetic diversity in several North American Allium species have provided information useful for germplasm conservation strategies. In a study examining the genetic diversity existing in three populations each of Allium columbianum and A. fibillum, over $90 \%$ of the diversity was found within-population for each species (Hellier, 2000). Thus, all of the analyzed populations for each species can be treated as one population while still maintaining a high level of biodiversity in the collection. A study investigating the genetic diversity in two other intermountain Allium species also found a high degree of within-species genetic variability not only in the narrowly restricted species (A. aaseae), but also in a widespread congener (A. simillimum) (Smith and Pham, 1996). The low levels of among-population genetic variability found in these two studies are similar to other outcrossing species (Hamrick and Godt, 1989). In species that show low genetic diversity within and high genetic diversity among populations, the source location becomes more of a determining factor in seed collection to avoid genetic erosion (Rogers, 2004). This also becomes an issue when propagating plants for reclamation or revegetation. In species with high levels of genetic diversity between populations, seed collected from one population might not produce plants best suited for survival in the area of reclamation (Lesica and Allendorf, 1999).

In an effort to increase our knowledge of genetic variation in intermountain Allium species, we have selected three species native to Utah for our study-A. acuminatum, $A$. brandegei, and $A$. passeyi-as described in McNeal and Jacobsen (2001). These species have widely varying ranges of distribution, rates of occurrence, and habitat preferences. Allium acuminatum is widely distributed and the most common Allium species in western North America. It appears to tolerate a wider range of habitats, occurring at elevations from 1210 and $2490 \mathrm{~m}$ (McNeal and Jacobsen, 2001; Shultz et al., 2006). In comparison, $A$. brandegei occupies a more narrow range of distribution but is relatively abundant in high elevation alpine and subalpine meadows throughout the northwest (McNeal and Jacobsen, 2001; Neely and Barkworth, 1984; Shultz et al., 2006). The third species in our study, A. passeyi, is a rare, localized endemic and appears to be limited to a very specific habitat occurring only in five populations in Box Elder County in north central Utah (Holmgren and Holmgren, 1974; McNeal and Jacobsen, 2001; Shultz et al., 2006). The objectives of this study are to better understand the genetic variation that exists within and among common and rare Allium populations.

\section{Materials and Methods}

Plant materials and DNA extraction. Fresh leaf material was collected in the wild at multiple locations for each species (Table 1 ) in the spring of 2005 . Five A. acuminatum, four $A$. passeyi, and three $A$. brandege $i$ sites were sampled. Samples were collected along a line transect to minimize potential clonal influence with distances between individuals varying according to the density of individuals at the site. Genomic DNA was extracted from leaf tissue of 192 individuals using the DNeasy 96 plant DNA extraction kit (two 96well plates) and MM300 mixer mill (Qiagen, Valencia, CA). Voucher specimens from each site were prepared from flowering plants in 2006 (Table 1) and submitted to the Intermountain Herbarium, at Utah State University, Logan, UT.

Amplified fragment length polymorphisms analysis. The AFLP technique was performed as described by Vos et al. (1995). Six selective primer combinations (E.ACCA// M.CAG, E.ACC//M.CAT, E.AGG//M.CAT, E.AGT//M.CTA, E.ACCA//M.CTC, E.ACAC// M.CTCT) were chosen with the universal $E c o$ RI and $M s e$ I adaptor sequences. Selective amplification reactions were replicated for each preamplified polymerase chain reaction template. The amplification products were size-fractionated using an ABI3730 instrument with $50-\mathrm{cm}$ capillaries, POP-7 polymer, Genescan 500 LIZ internal size standards, and Genescan software (PE Applied Biosystems, Foster City, CA). Individuals that produced low-quality DNA samples were excluded from analysis. A total of 104 individuals (46 A. acuminatum, $39 \mathrm{~A}$. passeyi, and $19 \mathrm{~A}$. brandegei) presented fragments evenly distributed throughout the entire profile, adequate for scoring. These GeneScan sample files were visually analyzed for the presence and absence of polymorphic DNA fragments, between 50 and 500 base pairs, using Genographer version 1.5 (Benham et al., 1999).

Table 1. Identification of the sampled populations, their site locations and global positioning satellite coordinates.

\begin{tabular}{llcc}
\hline Species/ID & \multicolumn{1}{c}{ Location } & Elevation (m) & Latitude, longitude \\
\hline A. acuminatum & & & \\
BC-1 & Blue Creek, Box Elder Co., UT & 1,556 & $41.94333^{\circ} \mathrm{N}, 112.42260^{\circ} \mathrm{W}$ \\
BC-2 & Blue Creek, Box Elder Co., UT & 1,652 & $41.93954^{\circ} \mathrm{N}, 112.41738^{\circ} \mathrm{W}$ \\
HR & Hardware Ranch, Cache Co., UT & 1,761 & $41.60985^{\circ} \mathrm{N}, 111.58331^{\circ} \mathrm{W}$ \\
LR & Liberty Road, Weber Co., UT & 1,870 & $41.35938^{\circ} \mathrm{N}, 111.90188^{\circ} \mathrm{W}$ \\
SF & Swan Flat, Cache Co., UT & 2,318 & $41.95702^{\circ} \mathrm{N}, 111.48882^{\circ} \mathrm{W}$ \\
A. passeyi & & & \\
GS & Golden Spike, Box Elder Co., UT & 1,546 & $41.63054^{\circ} \mathrm{N}, 112.49809^{\circ} \mathrm{W}$ \\
AH-1 & Anderson Hill, Box Elder Co., UT & 1,622 & $41.62616^{\circ} \mathrm{N}, 112.49790^{\circ} \mathrm{W}$ \\
AH-2 & Anderson Hill, Box Elder Co., UT & 1,638 & $41.81793^{\circ} \mathrm{N}, 112.44055^{\circ} \mathrm{W}$ \\
BC & Blue Creek, Box Elder Co., UT & 1,744 & $41.93906^{\circ} \mathrm{N}, 112.41613^{\circ} \mathrm{W}$ \\
A. brandegei & & & \\
LR & Liberty Road, Weber Co., UT & 1,859 & $41.35938^{\circ} \mathrm{N}, 111.90188^{\circ} \mathrm{W}$ \\
SF & Swan Flat, Cache Co., UT & 2,342 & $41.95702^{\circ} \mathrm{N}, 111.48882^{\circ} \mathrm{W}$ \\
TG & Tony Grove, Cache Co., UT & 2,515 & $41.89923^{\circ} \mathrm{N}, 111.64093^{\circ} \mathrm{W}$ \\
\hline
\end{tabular}
analyses of molecular variance (Excoffie et al., 1992), and neighbor-joining genetic distance analysis (Saitou and Nei, 1987) were used to investigate genetic diversity within and among populations.

Genetic distances between individual plants were determined by the numbers of AFLPs (Euclidean distance) and similarity coefficients computed as $2 \mathrm{~N}_{\mathrm{m}} /\left(\mathrm{N}_{\mathrm{x}}+\mathrm{N}_{\mathrm{y}}\right)$ in which $\mathrm{N}_{\mathrm{m}}$ is the number of pairs of bands matching between individuals and $\mathrm{N}_{\mathrm{x}}$ and $\mathrm{N}_{\mathrm{y}}$ are the total number of bands amplified from the individuals (Dice, 1945; Lynch, 1990; Nei and Li, 1979). Neither of these Euclidean distances nor similarity coefficients relies on shared null alleles. Analyses of variances based on pairwise comparisons of these similarity coefficients were performed using SAS (SAS Institute, Cary, NC) as described by Leonard et al. (1999).

In further analyses, the average number of pairwise differences among individuals in the sampled populations $\left(\mathrm{P}_{\mathrm{XY}}\right)$, average number of pairwise differences among individuals within populations $\left(\mathrm{P}_{\mathrm{X}}\right.$ and $\left.\mathrm{P}_{\mathrm{Y}}\right)$, corrected average pairwise differences among populations $\left[\mathrm{P}_{\mathrm{XY}}-\left(\mathrm{P}_{\mathrm{X}}+\mathrm{P}_{\mathrm{Y}}\right) / 2\right]$, and corresponding analysis of molecular variance based on $\mathrm{Eu}-$ clidean distances were computed using Arlequin (Excoffier et al., 1992).

Neighbor-joining trees were generated by PAUP* version 4.0b8 (Swofford, 2000) using the distance matrix generated by Arlequin (Excoffier et al., 1992) with the user-defined distance coefficient equal to the total number of marker differences between individual plants. Significance testing for the trees was performed using bootstrap resampling of 10,000 replicates. Graphic displays of the neighbor-joining trees were developed using TREEVIEW (Page, 1996).

\section{Results}

Genetic diversity within and among $A$. acuminatum collections. With the six selective primer combinations, AFLP analysis generated a total of 539 polymorphic loci. The average number of polymorphic bands per plant was significantly higher $(P<0.05)$ 
in individuals from the LR site in comparison with the lower elevation sites (Table 2). On this point, plants from the highest elevation site (SF) did not differ significantly when compared with the LR population, and although the average number of polymorphic bands in individuals from the SF site was higher than all of the lower elevation populations, these differences were only significant when compared with plants from the lowest elevation site. So we see that the two highest elevation sites have the highest average number of polymorphic fragments out of the groups tested, but only the LR site differed significantly in all of its comparisons (Table 2).

We performed a permutation test on the AFLP data for population subdivision using the similarity index as the basis for the test statistic. With the exception of comparisons with the BC-1 collection site, similarity coefficients were significantly lower between collection sites versus within collection sites (Table 3 ). The relatively small sample size from the BC-1 site limited the test power for comparisons with all but the largest site (HR) (Table 3 ). The HR group is significantly different from all other groups, and the BC-2 group is also significantly different in three of four comparisons (Table 3). Analysis of molecular variance (AMOVA) of AFLP data showed among-group variation accounting for $34 \%$ of the total variation observed in the $A$. acuminatum samples, whereas $66 \%$ of the variation was observed within groups. The overall $\Phi_{\mathrm{ST}}$ value for the sampled $A$. acuminatum sites was 0.339 , and the population pairwise $\Phi_{\mathrm{ST}}$ values ranged from 0.235 to 0.472 (Table 4).

Individual plants group together strictly by collection site in the neighbor-joining tree based on pairwise comparisons of the total number of DNA polymorphisms between individual plants (Fig. 1). Moreover, bootstrap confidence levels provide support hierarchical groups of BC-1, LR, and SF and also differentiate BC-2 from the other four collection sites. The most interesting aspect of this tree is the degree of differentiation between the two BC sites despite their proximity to each other $(\approx 600 \mathrm{~m})$, indicating a lack of gene flow between those two populations.

Genetic diversity within and among A. passeyi collections. Only five primer combinations were used in the $A$. passeyi analysis as a result of poor resolution resulting from one primer combination (E.ACCA//M.CAG). With the remaining five primer combinations, a total of 361 polymorphic bands were observed in the A. passeyi samples. The average number of polymorphic fragments per plant was significantly greater $(P<0.05)$ in the AH-2 collection compared with the other A. passeyi collections, which were not statistically different in fragment number (Table 2).

Between-group similarity coefficients were all lower than the within-group similarity coefficients in the compared groups, indicating differences in genotypes between groups. The two Anderson Hill collection sites (AH-1 and $\mathrm{AH}-2$ ) showed significant differences in their similarity index despite being separated by less than $1 \mathrm{~km}$. The sites separated by the furthest geographical distance (GS and $\mathrm{BC}$ ) also exhibited a significant difference in the between-group similarity index value (Table 5). AMOVA analysis of AFLP data showed among-group variation accounting for only $17 \%$ of the total variation observed with $83 \%$ of the observed variation occurring within groups. The overall $\Phi_{\mathrm{ST}}$ for the four $A$. passeyi populations was 0.174 with population pairwise $\Phi_{\mathrm{ST}}$ values ranging from 0.086 to 0.255 (Table 6).

The neighbor-joining tree constructed from the $A$. passeyi data (Fig. 2) reveals a closer relationship between groups than that groups. Fewer than 30 polymorphisms separate the least similar individuals.

Genetic diversity within and among $A$. brandegei collections. With the six selective primer combinations, AFLP analysis generated a total of 539 polymorphic loci. The average number of polymorphic fragments seen in the A. acuminatum and A. brandegei

per plant was significantly greater $(P<0.05)$ in individuals from the SF collection compared with the TG collection. The LR plants did not differ significantly from the other groups in the number of polymorphic fragments (Table 2).

Between-group similarity coefficients were all lower than the compared groups, and in most cases very low, suggesting genetic differentiation between populations, but sample sizes were too small to be confident of any significance (Table 7). AMOVA analysis of AFLP data showed among-group variation accounting for $36 \%$ of the total variation observed with $64 \%$ of the observed variation occurring within groups. Population pairwise $\Phi_{\mathrm{ST}}$ values were between 0.216 and 0.417 and had an overall mean of 0.355 (Table 8 ).

In the phenetic tree, each of the three collection groups segregate out very clearly with no overlap with the character differences being reflective of the geographical distances separating the sampling sites. The geographically closer sites (TG and SF) are paired more closely together (Fig. 3).

Table 2. Allium populations in order of increasing elevation with sample size, within-population similarity coefficient $(\hat{\mathrm{S}})$, and the average number of observed polymorphic bands per plant (ANPB). ${ }^{\mathrm{z}}$

\begin{tabular}{|c|c|c|c|c|c|c|}
\hline Species/ID & Elevation & $\mathrm{N}$ & $\hat{\mathrm{S}}$ & SE & ANPB & $\overline{\mathrm{SE}}$ \\
\hline \multicolumn{7}{|c|}{ A. acuminatum } \\
\hline BC-1 & $1,556 \mathrm{~m}$ & 5 & 0.577 & 0.013 & 146.0 & 7.0 \\
\hline $\mathrm{BC}-2$ & $1,652 \mathrm{~m}$ & 8 & 0.603 & 0.009 & 137.6 & 5.1 \\
\hline HR & $1,761 \mathrm{~m}$ & 14 & 0.600 & 0.012 & 147.4 & 5.6 \\
\hline LR & $1,870 \mathrm{~m}$ & 7 & 0.583 & 0.015 & 169.7 & 3.8 \\
\hline SF & $2,318 \mathrm{~m}$ & 12 & 0.664 & 0.008 & 158.8 & 3.3 \\
\hline \multicolumn{7}{|l|}{ A. passeyi } \\
\hline GS & $1,546 \mathrm{~m}$ & 10 & 0.608 & 0.016 & 130.8 & 4.2 \\
\hline AH-1 & $1,622 \mathrm{~m}$ & 11 & 0.566 & 0.015 & 128.2 & 5.2 \\
\hline AH-2 & $1,638 \mathrm{~m}$ & 8 & 0.630 & 0.018 & 147.6 & 4.2 \\
\hline $\mathrm{BC}$ & $1,744 \mathrm{~m}$ & 10 & 0.628 & 0.036 & 128.9 & 2.8 \\
\hline \multicolumn{7}{|c|}{ A. brandegei } \\
\hline LR & $1,859 \mathrm{~m}$ & 7 & 0.604 & 0.010 & 125.1 & 2.6 \\
\hline SF & $2,342 \mathrm{~m}$ & 5 & 0.545 & 0.015 & 129.6 & 6.1 \\
\hline TG & $2,515 \mathrm{~m}$ & 7 & 0.552 & 0.015 & 114.9 & 4.9 \\
\hline
\end{tabular}

${ }^{\mathrm{z}} \mathrm{SE}$ values are shown for the similarity coefficients and band number.

Table 3. Allium acuminatum mean similarity index values within (diagonal) and between (below diagonal) A. acuminatum sampling sites. ${ }^{2}$

\begin{tabular}{lrlllll}
\hline Population & $\mathrm{N}$ & $\mathrm{BC}-1$ & $\mathrm{BC}-2$ & HR & LR & SF \\
\hline Blue Creek 1 & 5 & 0.577 & & & & \\
Blue Creek 2 & 8 & 0.414 & 0.603 & & & \\
Hardware Ranch & 14 & $0.330^{*}$ & $0.478^{*}$ & 0.600 & & \\
Liberty Road & 7 & 0.445 & $0.313^{*}$ & $0.410^{*}$ & 0.583 & 0.664 \\
Swan Flat & 12 & 0.439 & $0.311^{*}$ & $0.436^{*}$ & $0.510^{*}$ & 0.664 \\
\hline
\end{tabular}

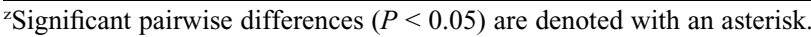

Table 4. Allium acuminatum pairwise comparisons of the average number of polymorphisms, between individual plants, within groups $\left(\mathrm{P}_{\mathrm{X}}\right.$ or $\left.\mathrm{P}_{\mathrm{Y}}\right)$ (diagonal); the average total number of DNA polymorphisms between groups $\left(\mathrm{P}_{\mathrm{XY}}\right)$ (above diagonal); the corrected number of DNA polymorphisms between groups $\left(\mathrm{P}_{\mathrm{XY}}-\left(\mathrm{P}_{\mathrm{X} 1}+\mathrm{P}_{\mathrm{X} 2}\right) / 2\right)$ (below diagonal); and the proportion of DNA polymorphism among groups $\left(\Phi_{\mathrm{ST}}=\right.$ average corrected number of polymorphisms/average total number of polymorphisms) (in parentheses, below diagonal).

\begin{tabular}{lrccccc}
\hline Population & N & BC-1 & BC-2 & HR & LR & SF \\
\hline Blue Creek 1 & 5 & 123.2 & 165.8 & 196.1 & 175.1 & 170.9 \\
Blue Creek 2 & 8 & $49.6^{*}(0.305)$ & 109.2 & 148.7 & 210.8 & 203.9 \\
Hardware Ranch & 14 & $75.8^{*}(0.391)$ & $35.4^{*}(0.235)$ & 117.4 & 186.5 & 172.1 \\
Liberty Road & 7 & $42.8^{*}(0.239)$ & $85.5^{*}(0.409)$ & $57.1 *(0.317)$ & 141.4 & 160.7 \\
Swan Flat & 12 & $56.0^{*}(0.340)$ & $96.0^{*}(0.472)$ & $60.1 *(0.348)$ & $36.7 *(0.242)$ & 106.5 \\
\hline
\end{tabular}

$* P<0.001$ significant level of divergence based on permutation test described by Excoffier et al. (1992). 


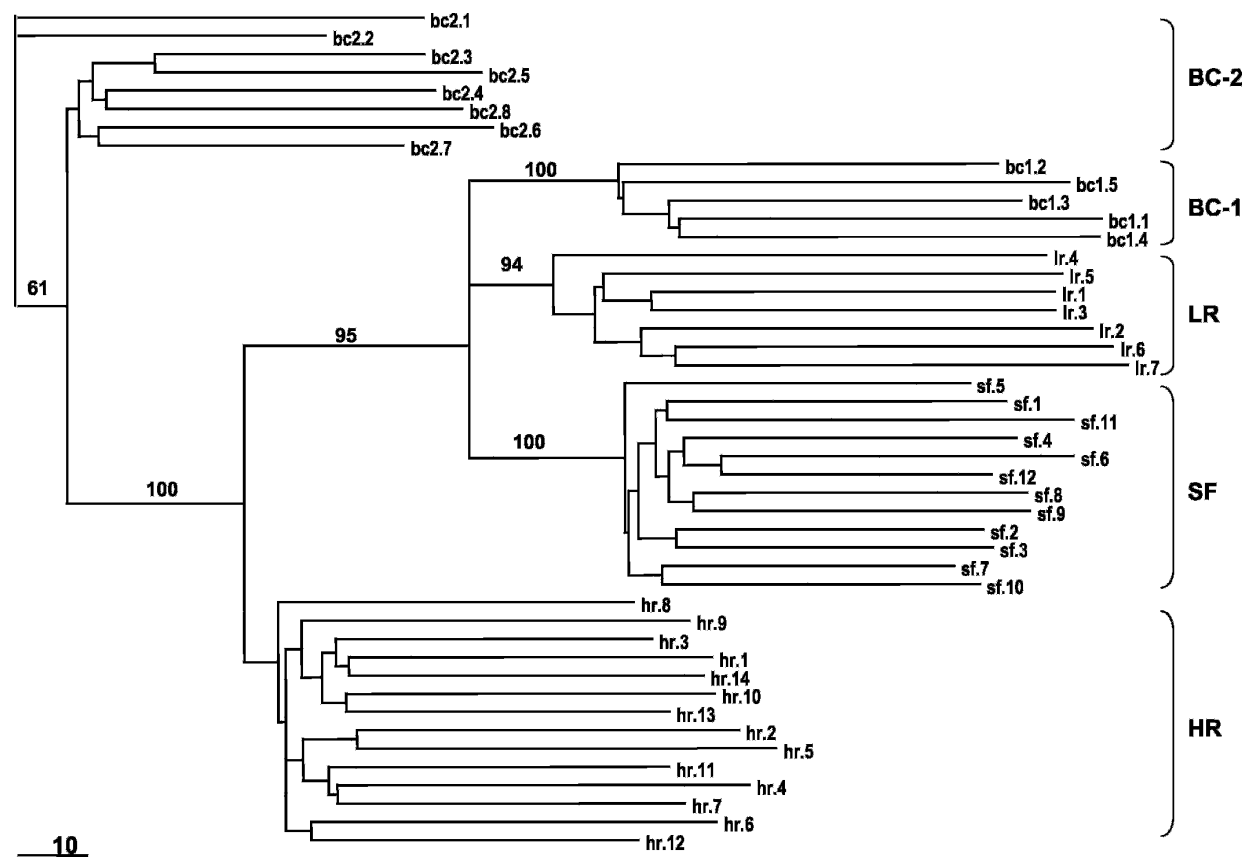

Fig. 1. Neighbor-joining tree constructed from amplified fragment length polymorphism data from the five sampled Allium acuminatum collection sites. Acronyms correspond to sites listed in Table 1 . The marker in the lower left-hand corner represents a distance of 10 character differences or polymorphisms. The neighbor-joining genetic distance analysis (Saitou and Nei, 1987) was based on a user-defined Euclidean distance matrix of the total number of character differences between individual plants from Arlequin (Excoffier et al., 1992) using PAUP* version 4.0b10 (Swofford, 2000). Significance testing for the trees was performed using bootstrap resampling of 10,000 replicates. A graphic display of the neighbor-joining tree was developed using TREEVIEW (Page, 1996).

\section{Discussion}

The sampling scheme used in this study allows us to look for patterns of withinspecies genetic diversity in relation to geographical distribution, abundance, and site elevation. The sampling of $A$. passeyi sites occurred over the species' known range of distribution, thereby providing comprehensive information on the patterns of genetic diversity found in this species. However, inferences drawn from the $A$. acuminatum and $A$. brandegei data are limited as a result

Table 5. Allium passeyi mean similarity index values within (diagonal) and between (below diagonal) A. acuminatum sampling sites. ${ }^{2}$

\begin{tabular}{lrlccc}
\hline Population & $\mathrm{N}$ & GS & AH-1 & AH-2 & BC \\
\hline Golden & & & & & \\
$\quad \begin{array}{l}\text { Spike } \\
\text { Anderson }\end{array}$ & 10 & 0.608 & & & \\
$\quad$ Hill 1 & 11 & 0.517 & 0.566 & & \\
Anderson & & & & & \\
$\quad$ Hill 2 & 8 & 0.529 & $0.562^{*}$ & 0.630 & \\
Blue Creek & 10 & $0.527^{*}$ & 0.512 & 0.503 & 0.628 \\
\hline
\end{tabular}

${ }^{\mathrm{z}}$ Significant pairwise differences $(P<0.05)$ are denoted with an asterisk.

Table 6. Allium passeyi pairwise comparisons of the average number of polymorphisms, between individual plants, within groups $\left(\mathrm{P}_{\mathrm{X}}\right.$ or $\left.\mathrm{P}_{\mathrm{Y}}\right)$ (diagonal); the average total number of DNA polymorphisms between groups $\left(\mathrm{P}_{\mathrm{XY}}\right)$ (above diagonal); the corrected number of DNA polymorphisms between groups $\left(\mathrm{P}_{\mathrm{XY}}-\left(\mathrm{P}_{\mathrm{X} 1}+\mathrm{P}_{\mathrm{X} 2}\right) / 2\right)$ (below diagonal); and the proportion of DNA polymorphism among groups $\left(\Phi_{\mathrm{ST}}=\right.$ average corrected number of polymorphisms/average total number of polymorphisms) (in parentheses, below diagonal).

\begin{tabular}{lrcccr}
\hline Population & N & GS & AH-1 & AH-2 & BC \\
\hline Golden Spike & 10 & 102.0 & 130.8 & 124.6 & 122.4 \\
Anderson Hill 1 & 11 & $25.3^{*}(0.145)$ & 108.8 & 120.2 & 137.0 \\
Anderson Hill 2 & 8 & $18.2^{*}(0.195)$ & $10.4^{*}(0.086)$ & 110.7 & 125.0 \\
Blue Creek & 10 & $23.5^{*}(0.192)$ & $34.7^{*}(0.173)$ & $21.7^{*}(0.255)$ & 95.8 \\
\hline
\end{tabular}

$* P<0.001$ significant level of divergence based on permutation test described by Excoffier et al. (1992).

of our sampling in only one region of their larger distributional range.

Most Allium species, including those in our study, are known to produce viable seeds (Kamenetsky and Rabinowitch, 2006). Natural vegetative propagation also occurs in many Allium species, although the rate of vegetative and is generally low (Kamenetsky our study are able to reproduce clonally by means of bulb division, although field studies tend to suggest that clonal reproduction occurs at a lower rate than sexual reproduction (Phillips, unpublished data). It is common for the mating system of a species to play a critical role in the patterns of genetic diversity within and among populations, but the dominant nature of AFLP markers does not provide direct information on the mating systems of the studied species. However, the partitioning of molecular variance can give clues to the mode of reproduction. A high ependence on asexual reproduction would population genetic diversity and the existence of genetically identical individuals. In populations relying primarily on sexual re- production, outcrossing species would tend to have a larger proportion of their total genetic variation occurring within populations in comparison with selfing species (Hamrick and Godt, 1989; Hellier, 2000). Because all individuals in the three species in our study exhibited unique AFLP phenotypes, we can assume that asexual reproduction plays no more than a minor role in their mode of reproduction. The high levels of variability maintained within populations compared with the between-population variability suggest outcrossing as the most likely mating system. The results of this study affirmed the importance of sexual reproduction and pollinator service in these species.

Partitioning of genetic variability by AMOVA revealed that the diversity in all three species was largely distributed within populations. The percentage of variation found within the populations of the widespread congeners ( $A$. acuminatum and $A$. brandegei) was estimated to be $\approx 65 \%$, whereas the rare A. passeyi within-population genetic variation accounted for $83 \%$ of its total variation.

Much of the between-population variation appeared to result from isolation by distance. In general, the differences expressed in the population pairwise similarity coefficients appear to be correlated with the geographical distance between populations (Tables 3, 5, and 7). The neighbor-joining trees based on total character difference and the AMOVA population pairwise $\Phi_{\mathrm{ST}} \mathrm{S}$ also supported this correlation. In general, geographically closer populations within each species were genetically more similar to each other than to more distant populations.

However, there was one significant exception found in the A. acuminatum populations 


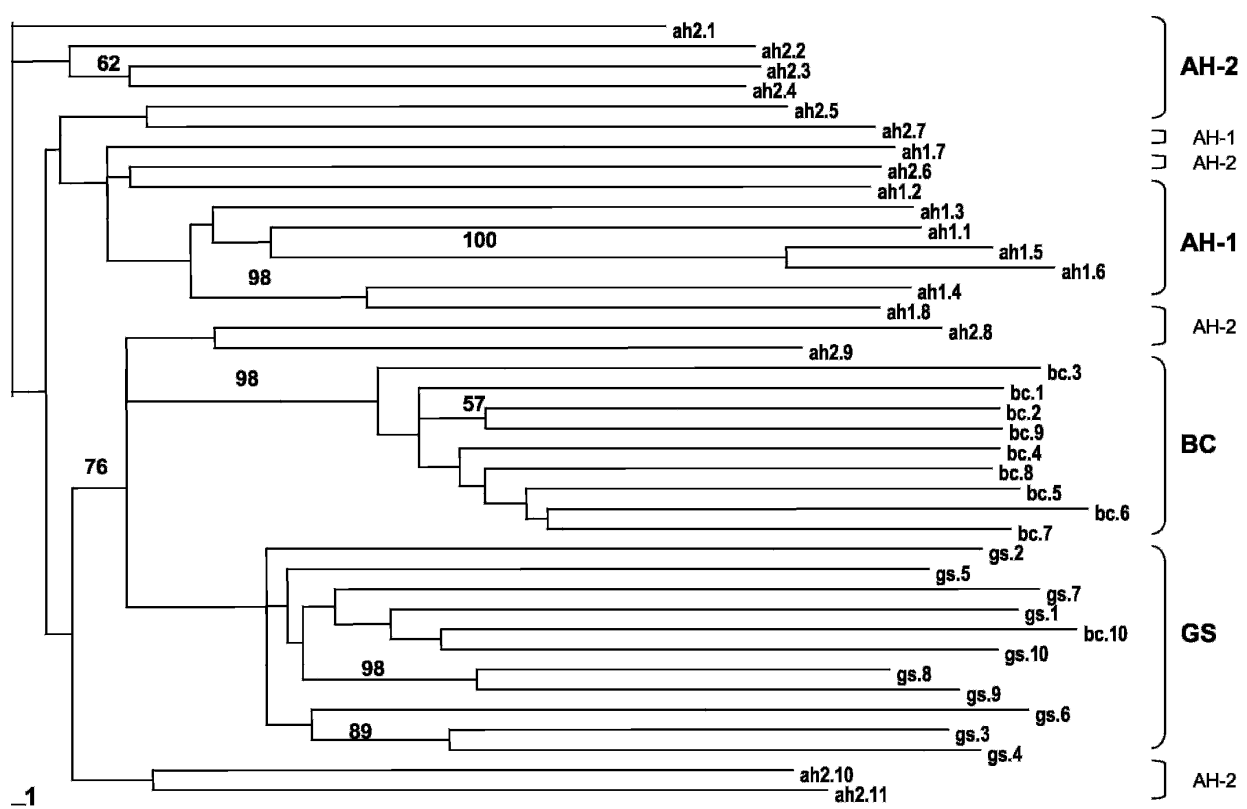

Fig. 2. Neighbor-joining tree constructed from amplified fragment length polymorphism data from the four sampled A. passeyi collection sites. Acronyms correspond to sites listed in Table 1. The marker in the lower left-hand corner represents a distance of one character difference or polymorphism. The neighbor-joining genetic distance analysis (Saitou and Nei, 1987) was based on a user-defined Euclidean distance matrix of the total number of character differences between individual plants from Arlequin (Excoffier et al., 1992) using PAUP* version 4.0b10 (Swofford, 2000). Significance testing for the trees was performed using bootstrap resampling of 10,000 replicates. A graphic display of the neighbor-joining tree was developed using TREEVIEW (Page, 1996).

we sampled. The BC-1 and BC-2 populations are only separated by $\approx 600 \mathrm{~m}$ but exhibit markedly dissimilar genotypes (Table 3; Fig. 1). Although our data are insufficient to give definite explanations for this anomaly, we can make some informed speculations.

A recent introduction event might account for the genotypic differences in these two populations. Their respective locations may provide clues as to how this could occur. BC1 is located on the edge of a dryland wheat field, and $\mathrm{BC}-2$ is found on a hillside reserved for hunting $\approx 100 \mathrm{~m}$ from a dirt road. One of the populations may be the result of unintentional anthropogenic seed dispersal where seed was transferred from another site in mud on a vehicle, farm implement, or the boot of a hunter.

Table 7. Allium brandegei mean similarity index values within (diagonal) and between (below diagonal) A. acuminatum sampling sites. ${ }^{z}$

\begin{tabular}{lcccc}
\hline Population & $\mathrm{N}$ & 1 & 2 & 3 \\
\hline Liberty Road & 7 & 0.604 & & \\
Swan Flat & 5 & 0.278 & 0.544 & \\
Tony Grove & 7 & 0.309 & 0.428 & 0.552 \\
\hline
\end{tabular}

${ }^{{ }^{2} \text { Significant pairwise differences }(P<0.05) \text { are }}$ denoted with an asterisk.
Temporal isolation is another possible explanation for the genetic differentiation between these two close populations. Despite the proximity of the two A. acuminatum populations, there are some distinct habitat differences that may impact reproductive timing at each site. Elevation and aspect differ greatly between the two populations. BC-1 is located on a gradual south-facing slope nearly $1000 \mathrm{~m}$ lower than BC-2, which is found on a steep northwest-facing slope. The elevation, grade, and aspect at each of these sites could change the microclimates enough to alter the timing of flowering in such a way that interpopulation crosspollination would not occur, rendering the populations reproductively isolated. Lack of gene flow resulting from isolation by time could lead to the divergence seen in our study. This form of adaptive divergence is supported by other studies of flowering plant species (Hendry and Day, 2005).

It is also possible that the observed genotypic differences in $\mathrm{BC}-1$ and $\mathrm{BC}-2$ are disproportionally inflated as a result of low sample sizes. The sampling of only five individuals from $\mathrm{BC}-1$ may not be adequately representative of the population as a whole.

Table 8. Allium brandegei pairwise comparisons of the average number of polymorphisms, between individual plants, within groups $\left(\mathrm{P}_{\mathrm{X}}\right.$ or $\left.\mathrm{P}_{\mathrm{Y}}\right)$ (diagonal); the average total number of DNA polymorphisms between groups $\left(\mathrm{P}_{\mathrm{XY}}\right)$ (above diagonal); the corrected number of DNA polymorphisms between groups $\left(\mathrm{P}_{\mathrm{XY}}-\left(\mathrm{P}_{\mathrm{X} 1}+\mathrm{P}_{\mathrm{X} 2}\right) / 2\right)$ (below diagonal); and the proportion of DNA polymorphism among groups $\left(\Phi_{\mathrm{ST}}=\right.$ average corrected number of polymorphisms/average total number of polymorphisms) (in parentheses, below diagonal).

\begin{tabular}{lcccc}
\hline Population & $\mathrm{N}$ & LR & SF & TG \\
\hline Liberty Road & 7 & 99.0 & 183.8 & 165.7 \\
Swan Flat & 5 & $75.5^{*}(0.417)$ & 117.8 & 139.7 \\
Tony Grove & 7 & $64.9 *(0.391)$ & $29.4^{*}(0.216)$ & 102.8 \\
\hline$* P<0.001$ significant level of divergence based on permutation test described by Excoffier et al. (1992).
\end{tabular}

Although the differences between $\mathrm{BC}-1$ and $\mathrm{BC}-2$ appear great on the phenetic tree (Fig. $1)$, it is important to note that the pairwise similarity coefficient is not statistically significant (Table 3).

The loss of genetic diversity, or genetic erosion, in a species is an important consideration in collection practices for restoration, conservation, or breeding purposes. One way that genetic erosion can be minimized by managers or propagators is by using practices based on familiarity with species-specific patterns of genetic diversity (Rogers, 2004). The study described in this article provides insight into patterns of diversity in intermountain Alliums as related to range of distribution, geographical distance or isolation, and altitudinal variation.

When comparing species, geographical range of distribution appears to play an important role in the genetic differentiation observed in this study. A measure of genetic divergence among populations can be quantified by computing $F$ statistics (Wright, 1965). $\Phi_{\text {ST }}$ values are often used as an estimation of divergence among populations. A $\Phi_{\mathrm{ST}}$ value of zero indicates no divergence, and a $\Phi_{\mathrm{ST}}$ value of one indicates a maximum divergence between populations. Wright (1965) suggested that values exceeding 0.2 demonstrate low rates of gene flow among populations.

Limited gene flow is especially evident in $A$. acuminatum and A. brandegei where AMOVA analysis showed high genetic differentiation between populations. Population pairwise $\Phi_{\mathrm{ST}}$ values among these two species ranged from 0.216 to 0.472 , whereas the narrowly distributed $A$. passeyi exhibited lower values between 0.086 and 0.255 . This disparity would be expected because sampling 


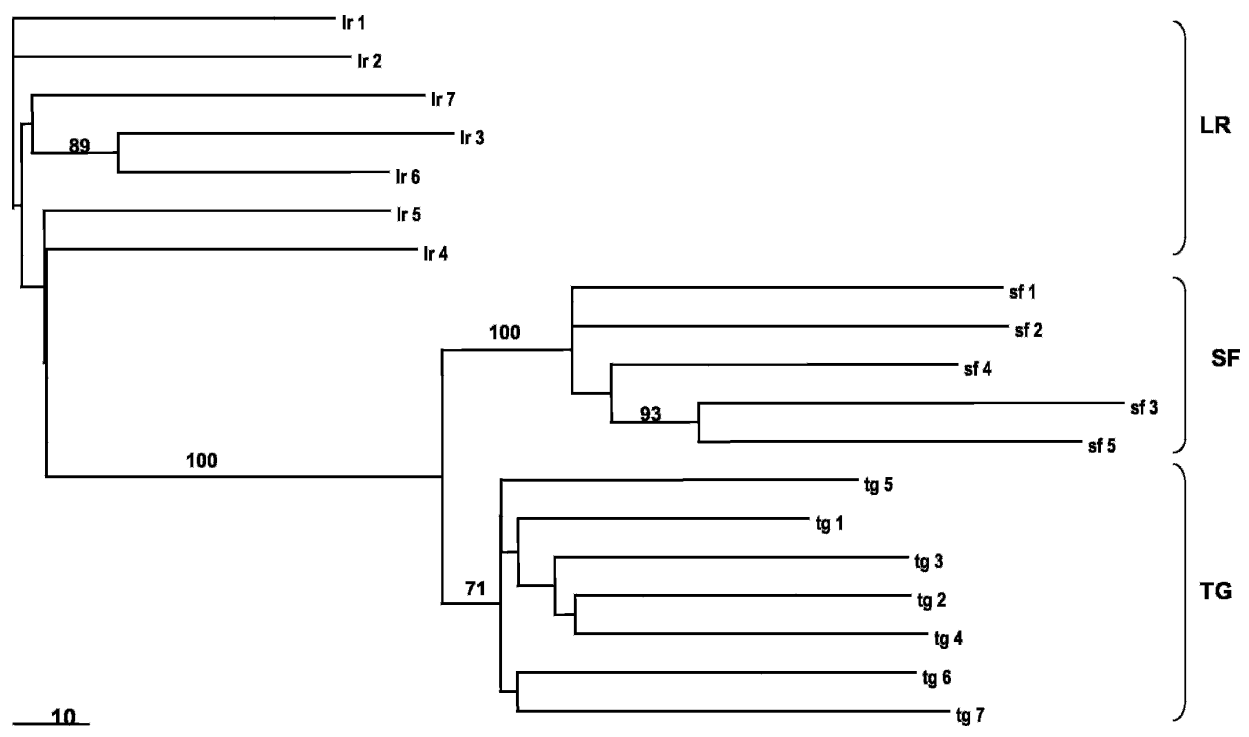

Fig. 3. Neighbor-joining tree constructed from amplified fragment length polymorphism data from the three sampled Allium brandegei collection sites. Acronyms correspond to sites listed in Table 1. The marker in the lower left-hand corner represents a distance of 10 character differences or polymorphisms. The neighbor-joining genetic distance analysis (Saitou and Nei, 1987) was based on a user-defined Euclidean distance matrix of the total number of character differences between individual plants from Arlequin (Excoffier et al., 1992) using PAUP* version 4.0b10 (Swofford, 2000). Significance testing for the trees was performed using bootstrap resampling of 10,000 replicates. A graphic display of the neighbor-joining tree was developed using TREEVIEW (Page, 1996).

in the A. acuminatum and $A$. brandegei populations occurred over a much larger geographical area than the $A$. passeyi samples, but when comparing pairwise $\Phi_{\mathrm{ST}}$ values between similarly distanced populations, we can see that the patterns of gene flow are not simply a function of distance, but may also reflect size of the species geographical range. For example, less than $1 \mathrm{~km}$ separates both of the two BC A. acuminatum populations and the two $\mathrm{AH} A$. passeyi populations. The pairwise $\Phi_{\mathrm{ST}}$ values between these two $A$. acuminatum populations is much higher (0.305) than that found in rare $A$. passeyi populations (0.086) sampled at a comparable distance. Pairwise $\Phi_{\mathrm{ST}}$ values between populations separated by 20 to $30 \mathrm{~km}$ are higher in three of the four $A$. passeyi comparisons $(0.255,0.173,0.195$, and 0.145$)$ than the more common $A$. brandegei populations (0.216). In populations separated by $\approx 50$ $\mathrm{km}$, the $A$. acuminatum again shows lower rates of gene flow (0.348 and 0.317$)$ than the rare $A$. passeyi (0.192). From these data we see that $A$. acuminatum demonstrated lower rates of gene flow than $A$. passeyi in all pairwise comparisons separated by similar distances. Comparing the rates of gene flow between similarly distanced populations in $A$. brandegei and $A$. passey $i$ was less meaningful as a result of only having one separation distance in common. These values suggest that interpopulation gene flow may be correlated with range size. In general, the higher pairwise $\Phi_{\mathrm{ST}}$ values in this study are found among the species with wide distributions. On the other hand, gene flow in the narrowly distributed species is considerably higher, and this is reflected in the higher levels of genetic similarity between $A$. passeyi populations (Table 5).

Similar trends are noticeable in the neighbor-joining trees (Fig. 1). Populations of the two more common species showed enough genetic difference that there was no overlap of individuals from different populations in the trees. However, the narrowly distributed and geographically closer $A$. passeyi showed less differentiation between populations. This is again reflected in the higher pairwise similarity index values of $A$. passeyi (Table 5).

AFLP data from A. acuminatum, A. passeyi, and $A$. brandegei has provided useful information regarding patterns of genetic variation within and among populations. The data confirm the importance of sexual reproduction and pollinator service. Isolation by distance can explain much of the observed variation with only a few exceptions. Our data also suggest that the widespread species in our study tend to have lower levels of interpopulation gene flow in comparison with the rare species. With this information, strategies can be used in an effort to identify diverse parental lines for breeding purposes, develop practical restoration guidelines, and improve conservation management plans.

\section{Literature Cited}

Adair, R., R.C. Johnson, B. Hellier, and W. Kaiser. 2006. Collecting tapertip onion (Allium acuminatum Hook.) in the Great Basin using traditional and GIS methods. Native Plants Journal 7:141-148.

Benham, J., J.-U. Jeung, M. Jasieniuk, V. Kanazin, and T. Blake. 1999. Genographer: A graphical tool for automated AFLP and microsatellite analysis. Journal of Agricultural Genomics 4: Article 4. Jan. 2007. <http://www.cabipublishing. org/gateways/jag/index.html $>$.

Bingham, R.A. and T.A. Ranker. 2000. Genetic diversity in alpine and foothill populations of Campanula rotundifolia (Campanulacea). Int. J. Plant Sci. 161:403-411.

Bjerregaard, L.S. 2004. Highly structured populations of a narrow endemic primrose. Utah State University, Logan, UT, Master's Thesis.
Brewster, J.L. and H.D. Rabinowitch (eds.). 1990. Onions and allied crops. Vol. 3. CRC Press, Boca Raton, FL.

Clausen, J., D.D. Keck, and W.M. Hiesey. 1940. Experimental studies on the nature of species. 1. Effect of varied environments on western North American plants. Carnegie Institution of Washington Publication No. 520. Washington, DC.

Dice, L.R. 1945. Measures of the amount of ecologic association between species. Ecology 26:297-302.

Excoffier, L., P.E. Smouse, and J.M. Quattro. 1992. Analysis of molecular variance inferred from metric distances among DNA haplotypes: Application to human mitochondrial DNA restriction data. Genetics 131:479-491.

Gitzendanner, M.A. and P.S. Soltis. 2000. Patterns of genetic variation in rare and widespread plant congeners. Amer. J. Bot. 87:783-792.

Hamrick, J.L. and J.W. Godt. 1989. Allozyme diversity in plant species, p. 43-63. In: Brown, A.H.D., M.T. Clegg, and A.L. Kahler (eds.). Plant population genetics, breeding, and genetic resources. Sinauer Associates, Sunderland, MA.

Hanelt, P. 2001. Alliaceae. In: Hanelt, P. (ed.). Mansgeld's encyclopedia of agricultural and horticultural crops. Vol. 4, 3rd ed. SpringerVerlag, Vienna.

Hellier, B. 2000. Genetic, morphologic, and habitat diversity of two species of Allium native to the Pacific Northwest, USA and their implications for in situ seed collection for the National Plant Germplasm System. Washington State University, Pullman WA, Master's Thesis.

Hendry, A.P. and T. Day. 2005. Population structure attributable to reproductive time: Isolation by time and adaptation by time. Mol. Ecol. 14:901-916.

Holmgren, N.H. and A.H. Holmgren. 1974. Three new species from the Great Basin. Brittonia 26:309-315.

Kamenetsky, R. and H.D. Rabinowitch. 2006. The genus Allium: A developmental and horticultural analysis. Hort. Rev. (Amer. Soc. Hort. Sci.) 32:329-337. 
Karron, J.D. 1987. A comparison of levels of genetic polymorphism and self-compatibility in geographically restricted and widespread plant congeners. Evol. Ecol. 1:47-58.

Leonard, A.C., S.E. Franson, V.S. Hertzberg, M.K. Smith, and G.P. Toth. 1999. Hypothesis testing with the similarity index. Mol. Ecol. 8:2105-2114.

Lesica, P. and F.W. Allendorf. 1999. Ecological genetics and the restoration of plant communities: Mix or match? Restor. Ecol. 7:42-50.

Lynch, M. 1990. The similarity index and DNA fingerprinting. Mol. Biol. Evol. 7:478-484

McNeal, D. and M. Ownbey. 1973. Bulb morphology in some western North American species of Allium. Madrono 22:10-23.

McNeal, D.W. and T.D. Jacobsen. 2001. Genus Allium. In: Flora of North America Editorial Committee (eds.). Flora of North America north of Mexico. Oxford University Press, New York, NY. 26:224-225.

Monsen, S.B. and N.L. Shaw. 2001. Development and use of plant resources for western wildlands, p. 47-61. In: McArthur, E.D., and D.J. Fairbanks (comps.). Shrubland ecosystem genetics and biodiversity: Proceedings; 2000
June 13-15; Provo, UT. Proc. RMRS-P-21. USDA-Forest Service, RMRS, Ogden, UT.

Neely, E. and M. Barkworth. 1984. Vegetation on soils derived from dolomite and quartzite in the Bear River Range, Utah: A comparative study. Bulletin of the Torrey Botanical Club 111:179 192.

Nei, M. and W.H. Li. 1979. Mathematical model for studying genetic variation in terms of restriction endonucleases. Proc. Natl. Acad. Sci. USA 76:5269-5273.

Page, R.D. 1996. Treeview: An application to display phylogenetic trees on personal computers. Comput. Appl. Biosci. 12:357-358.

del Rio, A.H. and J.B. Bamberg. 2002. Lack of association between genetic and geographic origin characteristics for the wild potato Solanum sucrense Hawkes. Amer. J. Potato Res 78:365-369.

Rogers, D.L. 2004. Genetic erosion: No longer just an agricultural issue. Native Plants Fall:113 122.

Saitou, N. and M. Nei. 1987. The neighbor-joining method: A new method for reconstructing phylogenetic trees. Mol. Biol. Evol. 4:406-425.
Shultz, L.M., D.R. Ramsey, and W. Lindquist. 2006. Revised atlas of Utah plants. College of Natural Resources, Utah State University, Logan, UT. 20 Jan. 2007. <http://earth.gis.usu. edu/plants/index.htmL $>$.

Smith, J. and T. Pham. 1996. Genetic diversity of the narrow endemic Allium aaseae (Alliaceae). Amer. J. Bot. 83:717-726.

Swofford, D.L. 2000. PAUP*. Phylogenetic analysis using parsimony (*and other methods). Version 4b10. Sinaur Associates, Sunderland, MA.

Vos, P.R., M. Hogers, M. Bleeker, T. Reijens, T. Van de Lee, M. Hornes, M. Frijters, L. Pot, J. Pelemen, M. Kuiper, and M. Zabeau. 1995. AFLP: A new technique for DNA fingerprinting. Nucleid Acids Res. 23:4407-4414.

Wen, C.S. and J.Y. Hsiao. 2001. Altitudinal genetic differentiation and diversity of Taiwan lily (Lilium longliflorum var formosanum; Liliaceae) using RAPD markers and morphological characters. Int. J. Plant Sci. 162:287-295.

Wright, S. 1965. The interpretation of population structure by $F$-statistics with special regard to systems of mating. Evolution Int. J. Org. Evolution 19:395-420. 